\title{
Técnicas de estragar os outros: sobre a ética xamânica na fronteira Brasil-Guiana
}

Technics to spoil others: about shamanic ethics in the frontier of Brazil and Guyana

\author{
Alessandro Roberto de Oliveira* \\ *Universidade de Brasília - Brasília, DF, Brasil \\ alessandro.robertodeoliveira@gmail.com
}




\title{
Resumo
}

Este artigo apresenta uma análise etnográfica sobre xamanismo no contexto pluriétnico do maciço guianense ocidental. Aborda particularmente sua modalidade agressiva que é definida regionalmente como ataque kanaimé. O universo sociocultural que caracteriza esse tipo de ação xamânica apresenta elementos de uma cosmo-ontologia que desafia a racionalidade ocidental, configurando modos de relação entre pessoas e plantas que colocam em jogo saberes específicos e práticas rituais. As reconfigurações contemporâneas dessas práticas xamânicas indicam o caráter aberto, a força e a heterogeneidade desse modo de conhecimento. A partir dos diferentes papéis exercidos por esses especialistas, o objetivo é trazer as reflexões indígenas sobre a ética do xamã na produção de malefícios e curas. $O$ argumento é que esse universo xamânico leva a noção de fronteira ao plano da comunicação interespecífica, reverberando interrogações sobre o estatuto do humano.

Palavras-chave: xamanismo; cosmo-ontologia; fronteira; humano-planta.

\begin{abstract}
This article presents an ethnographic analysis about shamanism in the pluriethinic context of the occidental Guiana massif. It addresses particularly the aggressive modality of shamanism that is regionally defined as kanaimé attack. The sociocultural universe that characterizes this kind of shamanic action presents elements of a cosmo-ontology that challenges the occidental rationality, configuring relationship modes between people and plants that put specific knowledges and ritual practices at stake. The contemporary reconfigurations of these shamanic practices indicate the open character, the strength and the heterogeneity of this knowledge mode. From the different parts rolled by shamanic specialists, the objective is to bring to light indigenous reflections about the shaman ethic on the production of malice and cure. The argument is that this shamanic universe brings the notion of frontier to the communication plan interspecific, reverberating interrogations about the statute of human.
\end{abstract}

Keywords: shamanism; cosmo-ontology; frontier; human-plant. 


\section{Introdução}

Essa noite foi perturbadora. Não consegui dormir. Acordei várias vezes com a sensação de que o punho da rede estava balançando. Sacava a lanterna sucessivamente. Mirava o nó da corda e não tinha nenhum movimento. No meio da madrugada ouvi os cavalos ao redor da casa. Depois ouvi arranhar a porta. Devem ter sido as vacas que ficam soltas no centro da aldeia à noite. Mas o arranhado passava da porta da frente para a única janela da casa, que fica do lado oposto. Essa noite eu senti medo do Kanaimé estar rondando por aqui. Dizem que ele não ataca os "brancos", mas na dúvida, sempre me aconselharam a manter o terçado por perto e não abrir a porta à noite para ninguém, em nenhuma hipótese. Hoje durante a tarde conversei com o senhor Nazareno sobre seu encontro com Kanaimé na roça e talvez isso tenha ficado na minha cabeça. Ou talvez era mesmo o "rabudo". ${ }^{1}$

Esse primeiro parágrafo é um extrato de meu diário de campo. Um registro de uma noite de junho na comunidade Jacamim, na terra indígena homônima situada na região Serra da Lua, onde fixei estadia durante o ano de 2011 para realizar minha pesquisa de doutorado. Mesmo antes de chegar à aldeia eu já conhecia algumas histórias sobre a modalidade de xamanismo agressivo recorrente em toda a região de serras e lavrados, particularmente na área hoje dividida pela fronteira entre o Brasil e a Guiana. Quando desembarquei em Boa Vista, capital de Roraima, no início daquele ano, presenciei técnicos da Fundação Nacional do Índio (Funai) mobilizados para apaziguar uma crise que ocorria na terra indígena Canauanim, na mesma região.

Naquele momento havia ocorrido uma série de ataques naquela comunidade e corria a notícia de que um grupo familiar recém-chegado da Guiana estava ameaçado de morte. As informações que chegavam à Funai eram de que as pessoas estavam se organizando para arrancar as plantas do terreiro da casa daquela família para evitar que os vegetais mudassem de casa e continuassem a praticar as mortes. Indigenistas e indígenas experientes nessas

1 A palavra Kanaimé é escrita de diferentes formas por diferentes autores (canaemé, kanaimé, kanaima) e ganha pequenas variações na pronúncia a depender do povo e da região. Na Guiana, por exemplo, os estudiosos grafam Kanaimo. Por uma questão de padronização para evitar confusões na leitura, sigo a forma atualmente grafada pelos índios em português: Kanaimé (e com inicial minúscula quando adjetivo). 
situações comentavam paralelamente que de nada adiantava arrancar as plantas, pois elas já teriam se transferido para as casas de outras pessoas da própria comunidade que haviam estabelecido convivência com os recém-chegados do país vizinho.

O universo sociocultural que caracteriza esse tipo de ação xamânica apresenta elementos de uma cosmo-ontologia que desafia os fundamentos do pensamento moderno ocidental, baseado na divisão e na purificação totalizante de domínios da "sociedade" e da "natureza" (Latour, 1994). O uso do termo cosmo-ontologia aqui se ampara no debate etnológico desenvolvido por proposições como a do animismo (Descola, 1992), que postula uma continuidade de caráter social entre humanos e não humanos nas ontologias ameríndias e, particularmente, no perspectivismo ameríndio (Viveiros de Castro, 1996), que recombina e dessubstancializa predicados subsumidos pelos grandes divisores no multiculturalismo moderno, especialmente os referentes ou atributos do estatuto do humano, já que no pensamento ameríndio eles não designam domínios ontológicos distintos, mas contextos relacionais, perspectivas móveis e variáveis entre quem é humano é quem não é. Particularmente no perspectivismo porque este tem no xamanismo seu fundamento teórico e campo de operação e xamãs são definidos nas ontologias ameríndias como "pessoas multinaturais por definição e ofício, [...] capazes de transitar entre as perspectivas, tuteando e sendo tuteados pelas subjetividades extra-humanas sem perder a própria condição de sujeito" (Viveiros de Castro, 1996, p. 135).

A partir da minha experiência etnográfica tomo como ponto de partida a compreensão do xamanismo como "instância privilegiada para a comunicação entre agentes humanos e não-humanos" (Sztutman, 2005, p. 153, grifo do autor), ou, como prefere este autor, um "sistema de comunicação e mediação" ao qual proponho infletir através de um recorte analítico processual em lugar da perspectiva sistêmica, direcionando atenção propriamente ao "campo de operação", isto é, às técnicas xamânicas, aqui compreendidas como um grupo particular de movimentos que põe em relação corpos, instrumentos e forças do cosmo.

Essa escolha me parece mais produtiva para abordar o estilo de xamanismo agressivo definido como ataque kanaimé. As reconfigurações contemporâneas das práticas xamânicas indicam o caráter aberto, a força e a heterogeneidade dessa instância comunicativa. Uma característica dessa modalidade de agressão é a ofensiva xamânica violenta como prelúdio ou parte de ataques físicos. 
Pretendo chamar atenção para as técnicas de "estragar" os outros - esse grupo de movimentos que põe em relação pessoas e plantas em um fluxo específico de atos que suscita a reflexão sobre o xamanismo como fronteira. Adianto em dizer que essa noção não é articulada no sentido de traçar a linha que une e separa humanos e não humanos, mas tampouco desconsiderar seus contornos, mas no sentido de matizá-los ou enviesá-los (Viveiros de Castro, 2008, p. 5) pela etnografia. A partir da contextualização dos diferentes papéis exercidos pelos xamãs, o objetivo deste artigo é dialogar com as reflexões indígenas sobre a ética do xamã na produção de malefícios e curas.

Meu aprendizado sobre esse universo xamânico se deu através de uma série de conversações sobre o tema com moradores da região Serra da Lua, principalmente em Jacamim. Por vias muito diversas, tive a oportunidade de ouvir histórias que explicam a origem do conhecimento xamânico entre os Wapichana; relatos de pessoas que viveram a experiência do ataque, e reflexões e proposições morais sobre a ética xamânica. Meu argumento é que, pensado como fronteira em termos processuais, esse campo de operação xamânica abre possibilidade para novas interrogações sobre o estatuto do humano a partir das técnicas que são empregadas para estragar os outros.

\section{Xamanismo agressivo na fronteira Brasil-Guiana}

O contexto da análise desenvolvida neste artigo circunscreve um fragmento da área etnográfica delineada por Melatti (2016) como maciço guianense ocidental. Essa macrorregião caracteriza-se por um ambiente heterogêneo e uma composição sociocultural muito diversa. O que permite recortá-lo como uma "área etnográfica" é a extensa rede de intercâmbio que liga os diferentes povos indígenas entre si, embora alguns deles tenham contato mais antigo com sociedades nacionais (como os Macuxi e Wapichana) e outros relativamente mais recente (como os Yanomami). Nesse nexo macrorregional a etnonímia expressa graus relativos de distância social em um sistema de identidades articulado há bastante tempo por intercasamentos e pela ocorrência de aldeias de população mista ou de estreita vizinhança entre aldeias de etnias distintas (Santilli, 1994). Soma-se a isso o fato de que os povos macuxi e wapichana incorporaram em seu universo cosmológico os eventos decorrentes de uma violenta história 
de expropriação territorial e imposição de uma fronteira internacional que dividiu o território tradicional de seus antepassados (Baines, 2003).

Nesse cenário a circulação de conhecimentos é um dos aspectos de integração regional (Colson, 1985). Ocorre nessa área uma intensa movimentação de pessoas e grupos que se dá por razões de ordem ecológica (rotatividade das áreas de cultivo, disponibilidade de recursos hídricos, incidência de caça); de ordem política (aparatos estatais de saúde e educação, formação e fissão de grupos) e cosmológica (infortúnios, feitiçaria, doenças, morte). Na epistemologia wapichana, por exemplo, a aquisição de conhecimento pressupõe movimento: é necessário conhecer espaços mais amplos que a própria aldeia de origem. $\mathrm{Na}$ juventude, rapazes solteiros costumam viajar por outras aldeias no Brasil e na Guiana, ou fixar-se por alguns períodos em trabalhos nas cidades, fazendas e garimpos. Nessas jornadas cada um constrói individualmente o seu corpo de experiências (Farage, 1997). ${ }^{2}$

Minha experiência etnográfica está relacionada principalmente aos Wapichana que vivem no interflúvio dos rios Branco, no Brasil, e Rupununi, na Guiana. Apesar de ter estabelecido maior familiaridade com pessoas que se identificam como Wapichana e desenvolvido algum aprendizado sobre a língua aruaque, reconheço analiticamente que qualquer abordagem que separa "sociedades" ou "grupos étnicos" como unidades discretas em termos socioculturais e/ou linguísticos é pouco rentável para compreender a complexidade das relações que ali se configuram, onde o transnacional, o nacional e o étnico coexistem de forma dinâmica, ambígua e paradoxal (Baines, 2006).

Diante desse contexto etnográfico torna-se mais produtivo pensar em termos da variação, do posicionamento, das trocas e das alterações, considerando os padrões de significado como resultado de muitos pontos de vista expressos por diferentes atores sociais a partir de suas posições (Barth, 2000). Nesse sentido, pesquisas lideradas por Gallois (2005) trouxeram uma importante

2 Os Wapichana são o único povo de filiação linguística aruaque que habita os campos do interflúvio Branco-Rupununi, região politicamente dividida entre o Brasil e a Guiana. Somam hoje uma população de aproximadamente 14 mil pessoas, sendo que 7832 vivem do lado brasileiro e 6000 indígenas no lado da Guiana, além de algumas famílias na Venezuela. No Brasil a maior concentração populacional wapichana localiza-se na região Serra da Lua. No lado guianense, suas aldeias ocupam as savanas do rio Rupununi, Tacutu e Kwitaro, tendo as montanhas Kanuku como limite norte, divisa com território macuxi, e ao sul com ocupação que se estende até as proximidades do território do povo waiwai. 
contribuição ao propor o deslocamento do recorte localista e "étnico" para as redes de relações e abriu espaço para outro olhar sobre as "Guianas", diferente dos modelos etnológicos clássicos para a região. Essas pesquisas abriram a possibilidade de abordar as redes para além do domínio exclusivamente humano, incluindo um plano cósmico da comunicação com os não humanos. ${ }^{3}$

Ao olhar para a área do interflúvio Branco-Rupununi sob essa perspectiva, o xamanismo revela um duplo aspecto dos fluxos de pessoas e conhecimentos: ao passo que articula extensas redes de intercâmbio e agressão, também expressa reinterpretações da noção de fronteira, no sentido étnico e nacional, entre grupos sociais. Para muitos Wapichana que vivem no Brasil, por exemplo, o estilo de vida de seus parentes guianenses é considerado mais tradicional. Os índios da Guiana ainda pescam com timbó e se reconhece lá os feiticeiros mais fortes (Ávila, 2009). Na perspectiva compartilhada pelos Wapichana o xamanismo agressivo é tido como uma invenção macuxi, povo caribe com o qual têm um passado de guerra e com o qual convivem de modo relativamente pacífico atualmente.

Apesar de escassa, a literatura etnográfica sobre os grupos aruaque nessa região registrou sistematicamente o fenômeno kanaimé. No início do século XX, William Farabee (2009) observou que entre os Wapichana toda moléstia ou morte era relacionada à má influência de outros, outras tribos ou outros parentes, via de regra, sob controle de um feiticeiro. No meio do século, Gioconda Mussolini escreveu sobre a crença "vapidiana" no fato de a morte estar sempre associada à atuação de maus espíritos (agindo por conta própria ou por influência de um terceiro) que arrebatam ou eliminam a vítima (Mussolini, 1980).

Já Nádia Farage (1997) ponderou que a interpretação do fato kanaimé pela literatura etnográfica se prendeu a um horizonte funcionalista como mecanismo demarcador de fronteiras de grupos, designando inimigos e predadores, e salientou que algo do conceito kanaimé escapou a essas interpretações. Farage observou que Koch-Grünberg (1982) já havia chamado atenção para uma dimensão fundamental das ações kanaimé: o furor da vingança que toma conta do sujeito e o impele à ação. Nessa hipótese levantada pelo etnólogo alemão, o conceito kanaimé desdobra-se no campo da ética e da condição

3 Os estudos organizados por Gallois abordaram as redes de relações indígenas na região do Uaçá no baixo rio Oiapoque, e na região do Amapá, norte do Pará e Roraima. 
humana, antecipando, por décadas, um debate que se tornou central na etnologia guianense com os trabalhos de Joanna Overing $(1985,1991,1995,2002)$. São essas duas dimensões que me interessam recuperar neste trabalho: a condição humana nas ações kanaimé e as avaliações contemporâneas sobre a ética do xamã na passagem da convivência pacífica à destruição dos outros.

\section{O saber soprar}

O xamã entre os Wapichana é definido pelo termo marinao. Essa figura é detentora de um conhecimento altamente especializado e goza de prestigiosa reputação por suas competências na atividade de aplacar males que provocam doenças e morte. O marinao é o mediador das relações entre o mundo dos vivos e o dos mortos, cujos habitantes sabe influenciar e pôr ao seu serviço. A origem desse conhecimento me foi descrita evocando outro tempo, aquele das aventuras dos irmãos demiurgos em face de diferentes gentes-bichos, avós primordiais que deram origem ao mundo atual. No tempo da origem, a explosão do corpo de uma velha-avó poluiu o mundo com as doenças que se conhece hoje. Fugindo dessas doenças o demiurgo Duid teria encontrado com o velho Kanukushi - e esse encontro deu origem ao "saber soprar". Originais dos ventos das serras, os sopros são fórmulas usadas para proteção contra os bichos e para a cura de enfermidades. Atualmente o soprar muitas vezes é traduzido como "reza". Contra o poder de devoração dos bichos "tem que soprar pensando no nosso irmão Jesus Cristo" me disse um especialista, em uma expressão que sinaliza o caráter aberto do conhecimento xamânico.

G. Mussolini descreveu o trabalho do marinao entre os Wapichana como o de um "médico-feiticeiro". Por ocasião de moléstias como separação e fuga da alma de uma pessoa, o marinao realiza sessões de cura nas quais andava até as serras à procura da "sombra" do doente para recuperá-la e devolvê-la ao seu verdadeiro corpo. Segundo Mussolini (1980, p. 198):

Durante a cura, o tabaco é empregado: traga-lhe a fumaça e bebe-se o suco. Fumando, o marinau vê, através da fumaça, seus parentes mortos. Desta forma, chega a participar do mundo dos mortos, pondo-se em contato com os "maoaris" que o advertem sobre os meios de conseguir a cura. Parece repetir-se entre os 
Vapidiana o que se verifica entre os Taulipangue: os pajés, pela sua arte ventríloqua, chamam em seu auxílio espíritos que aparentemente vêm do alto e descem fazendo grande barulho. O diálogo que se trava entre eles (pelo talento do pajé em imitar outras vozes e gritos de animais), atrai para a pessoa do médico-feiticeiro o prestígio que escapa ao comum dos homens.

Essa dialogia entre o xamã e animais-espíritos também foi observada por Farage (1997) no repertório de cantos upurz karawau, constituído de cantos-correntes que ao mesmo tempo lançam sua alma para o alto e o prendem à sua vida terrena, não o deixando perder-se na viagem. É a partir da leveza do canto, acompanhado pelo ritmo de um molho de folhas de ingá ou pau-tipiti, que o marinao consegue subir e visitar esferas mais altas e inacessíveis enquanto outros falam em seu lugar durante as sessões xamânicas.

A iniciação do marinao não deriva propriamente de uma decisão pessoal, mas de circunstâncias como situações de crise, doença pessoal ou perda familiar. A aprendizagem consiste, sobretudo, na aquisição do canto. O período de aquisição de um repertório de cantos é entendido como a feitura ou entrega da corrente - e requer reclusão do iniciando, tempo de abstinência sexual e rigorosa dieta alimentar que paraleliza com outras situações de resguardo como a doença ou o parto. Tal esforço é complementado pela ingestão continuada, pelas narinas e pela boca, de infusão de água, tabaco e uma categoria específica de plantas. Essas plantas mesclam-se à própria natureza do xamã e passam a fazer parte indissociável de sua pessoa. Acrescente-se ainda à pessoa do xamã os outros xamãs mortos e os seus minkiaru (auxiliares ou companheiros).

As diferenças entre os marinao e as pessoas comuns aludidas por G. Mussolini são notáveis em diferentes aspectos. Tal distinção se expressa no fato de terem memória individual preservada e serem lembrados por seus nomes pessoais, pela fama de seus poderes e por suas profecias. Entre os poderes atribuídos aos marinao está a competência para comunicar-se com este outro mundo dos xamãs que se transformaram em "espíritos" e vivem nas serras, além da capacidade de transformar-se em outros seres, como pássaros ou serpentes, e percorrer longas distâncias em espaço mínimo de tempo. Os marinao também seguem destino diverso das pessoas comuns após a morte e passam a viver em uma grande árvore denominada Toronai, que fica no topo 
de uma serra muito alta. Esta árvore é chamada de "banco do marinao", e corresponde a um pé descomunal de maruai. ${ }^{4}$ Lá os xamãs se casam e têm filhos. Organizam-se por uma hierarquia do conhecimento na qual os muito sábios ficam no topo e aqueles menos sábios ficam embaixo, onde recebem dejetos dos que se encontram na parte superior.

Seguindo a terminologia proposta por S. Hugh-Jones (1996) o xamanismo entre os Wapichana em consonância com o padrão recorrente nas Guianas é tipicamente "horizontal", de distribuição relativamente isomórfica com poderes provenientes de inspiração e carisma presente em sociedades igualitárias e belicosas. Encontram-se aqui variações das formas de ação criando ambientes fronteiriços entre as figuras do marinao (que bate folha), do popazo (rezador) que seria uma inflexão "vertical" e do chanaminuru - xamã dedicado a espalhar a morte e a doença, especialista em "estragar" as pessoas. Essas variações marcam a ambiguidade moral quanto à ética do xamã, pessoa que pode ser percebida por alguns como um bom marinao, "curador" ou "rezador" e por outros como um chanaminuru. A definição é sempre fruto de um julgamento moral e dependente da posição daquele que julga. Esses perfis gravitam nessa fronteira borrada entre práticas curativas e agressivas. Tal ambiguidade marca uma singularidade do xamanismo nessa região: o fato de que o xamã não é o sujeito que protege seu socius contra o exterior. Não existe vínculo necessário entre o xamã e a aldeia onde reside e ao contrário de "projetar uma identidade do grupo local, o xamã, para os Wapichana, constitui a possibilidade de introjeção da alteridade" (Farage, 1997, p. 272) no interior de uma comunidade.

Por essa razão, doentes geralmente procuram atendimento xamanístico fora de seus locais de moradia e empreendem grandes viagens em busca de tratamento. Em toda a região do lavrado existe uma intensa procura pelos serviços xamânicos. Essa rede de atendimento envolve xamãs de aldeias distantes, pertencentes a grupos étnicos distintos, bem como especialistas "maranhenses", cujos poderes são reconhecidos por muitos moradores das áreas indígenas que buscam seus préstimos na cidade. Boa Vista é um polo nesse sentido. Nos bairros periféricos da capital encontram-se xamãs que atuam a partir de diferentes tradições de conhecimento, instrumentos e técnicas, combinando influências

4 Um tipo de resina perfumada usada em diversos momentos rituais. 
da "magia negra" e da "macumba", incorporando práticas desenvolvidas por especialistas não indígenas.

Nesse quadro, a distância contribui para que um especialista seja reputado como marinao poderoso e o perigo é inversamente maior em razão da proximidade social do especialista. Por essa razão, são inúmeros os casos de assassinato do xamã por seu grupo local em circunstâncias de crises.

\section{Vida de pajé, vida de Kanaimé}

O estilo de xamanismo agressivo expresso nas ações de ataque violento praticadas por Kanaimé é de ampla distribuição em toda região de fronteira entre o Brasil e a Guiana e tópico recorrente na literatura etnográfica guianense desde o século XIX. Viajantes, missionários, pesquisadores e profissionais da saúde que visitaram ou viveram na região colecionaram histórias funestas sobre episódios de morte associados pelos índios à ação kanaimé.

Richard Schomburgk (1931) viajou ao interior da Guiana entre os anos de 1835-1839 e interpretou o Kanaimé como um inimigo invisível, uma essência demoníaca. Em muitos casos associado a uma personalidade individual, seria um método de vingança indígena, um pesadelo opressivo que os persegue ininterruptamente, os fazendo fechar a porta de casa no final do dia e acreditar que reconheçam sua presença nos ruídos estranhos da noite. O botânico alemão foi preciso ao descrever o caráter pervasivo das preocupações em identificar e prever ataques e como a ideia de Kanaimé impregna toda a paisagem. Em 1887, o viajante $\mathrm{H}$. Coudreau chegou a lamentar a vulgaridade da insistência dos Wapichana no assunto. No início do século XX, Farabee (2009) classificou a sensação de ameaça constante expressa pelos Wapichana como algo indescritível.

Em certo sentido, os Wapichana tendem a acusar de Kanaimé os outros povos ou indivíduos, provenientes de aldeias distantes, que consideram brabos. Rabudo, sinônimo de Kanaimé, é uma alusão à selvageria. O termo também é usado em sentido metafórico, para apelidar Kanaimé às crianças teimosas, bem como para descrever uma concepção do contato interétnico e da invasão territorial que viveram (Foster, 1993).

Associado à guerra e à feitiçaria, o fato kanaimé foi interpretado pela literatura etnográfica regional como mecanismo de demarcação de fronteiras 
de grupo. Entretanto, T. Koch-Grünberg interpretou Kanaimé como o furor da vingança. Um homem pode tomar a decisão de se tornar um Kanaimé, uma vez esgotados outros meios de obter esse desejo de revanche. Aqueles que tomam essa decisão abandonam suas famílias e amigos e devotam sua vida e energia à realização dessa finalidade. Depois de concretizar o projeto de vingança, o Kanaimé pode se voltar contra pessoas inocentes. Alimenta-se de certas substâncias que têm a potência de torná-lo invisível. Por essa razão, sua atuação se evidencia apenas a posteriori, pelas marcas roxas que deixa no corpo da vítima.

Como um fenômeno regional, Kanaimé é vivido por diversos povos. É um termo recorrente na literatura etnográfica para descrever um modo ritual de ataques, mutilações, assassinatos e seus praticantes; além de aludir à ideia mais difusa sobre atividades espirituais malignas que consome os assassinos. Pervasivo e profundo, o discurso sobre Kanaimé dramatiza a condição humana e reflete aspectos éticos da convivência, configurando um fato central na vida indígena. Como um conceito, Kanaimé é utilizado em vários níveis de significação, referindo-se às dinâmicas do mundo espiritual, às agressões físicas sofridas por indivíduos, às tensões entre aldeias e famílias e às suspeitas de estrangeiros de um modo geral. N. L. Whitehead (2002) usou a expressão poética para sugerir que o sentido da agressão e da morte violenta não pode ser entendido apenas por referência às fundamentações biológicas, funções sociológicas, necessidades materiais ou ecológicas, mas como uma expressão cultural complexa e fundamental dos povos que vivem nessa região.

É impossível determinar a origem histórica do fenômeno, pois o que se tem são relatos que remetem a pelo menos 200 anos de sua prática e interpretação, produzidos por fontes coloniais, textos antropológicos e literários (Whitehead, 2002). As referências escritas sobre Kanaimé aparecem nas fontes europeias a partir do século XIX, em um quadro de informações coloniais, como um modo de ação militar colocado em prática em excursões de comércio e invasões predatórias pelos Akawaio, povo caribe habitante da área de montanhas situadas na região ocidental da Guiana e que vive ao longo do rio Mazaruni e seus afluentes, fazendo vizinhança com os Macuxi e os Patamuna.

De acordo com os registros coloniais examinados por Whitehead (2002), esse povo realizava expedições de longa distância e abria guerra contra diferentes grupos habitantes das montanhas utilizando o expediente de ataques 
noturnos, quando escondia a fraqueza de seu número e espalhava o terror através de atividades chamadas kanaimé. Haveria surgido nesse contexto uma definição de Kanaimé como aquele a quem os índios atribuem todos os males, doenças e mortes. Um tipo de inimigo vingador que não descansa enquanto não matar suas vítimas, fazendo uso do envenenamento. Essa definição precedeu os principais elementos do universo kanaimé e das subsequentes abordagens desde o século XIX aos dias atuais.

Whitehead (2002) estudou o fenômeno kanaimé entre os Patamuna e Macuxi que vivem na região das montanhas de Pacaraima, na Guiana. Este antropólogo abordou como o universo kanaimé foi representado não só por indígenas, mas por campanhas de terror colocadas em prática pelo Estado guianense. Vidal e Whitehead (2004) analisaram como Kanaimé também foi mimeticamente associado à violência das ondas de desenvolvimento econômico e político na região, como no caso da fronteira da mineração e seus efeitos nas práticas de Kanaimé entre os Patamuna.

Whitehead cogita a hipótese de que, do mesmo modo que o alleluia foi inventado pelo complexo xamânico caribe diante de um novo contexto de evangelização - no qual os povos indígenas articularam seus conhecimentos mágico-religiosos à doutrina trazida por missionários anglicanos criando um novo ritual - pode ser que os xamãs macuxi tenham elaborado os elementos rituais e mágicos do complexo kanaimé. A base dessa hipótese é a ligação histórica entre o fato kanaimé, o advento das armas de fogo na região e a situação em que os Macuxi também foram incessantemente predados por outros povos, especialmente os Karinya. Nessa acepção, Kanaimé pode ter emergido como uma técnica defensiva frente à nova força militar esmagadora, bem como uma forma de responder a novas situações do contato.

\section{Ação kanaimé: campo de operação}

Aproximando a literatura sobre a região e as narrativas e relatos ouvidos em campo é possível descrever os padrões da ação kanaimé e o seu campo de operação. A iminência de um ataque kanaimé pode ser percebida através de certos sinais evidenciados em casa, durante a noite. Pode ser o chamado de uma ave de hábitos noturnos como uma coruja ou um curiango. Um som 
de assovio, um movimento ao longo da base das paredes da casa que pode ser notado através de uma rachadura na parede ou através de uma janela entreaberta. A pessoa pode sentir um ligeiro puxar das cordas de sua rede. O sinal indubitável é a presença de uma ou mais cobras venenosas dentro de casa na manhã seguinte.

Apesar desses sinais, os ataques kanaimé geralmente não são antecipados e ocorrem quando uma pessoa está sozinha em uma roça ou um caminho. A certa distância do observador, um pequeno arbusto ou planta pode começar a balançar de modo estranho aos movimentos normais causados pelo vento. Kanaimé pode aparecer para a vítima diretamente como um humano, na mata como uma onça ou como um tamanduá na savana. Essa figura tem a potência de aparecer ao longe e, rapidamente, surgir bem próxima ou atrás da pessoa.

Depois desses sinais, um ataque físico direto e mais completo pode acontecer a qualquer momento, até mesmo anos depois. Durante o período de perseguição, o Kanaimé utiliza técnicas de caça seguindo as pegadas e os rastros da vítima pelos caminhos e também usa técnicas de encantação e sopro ritual, que o permite ocultar a identidade física e realizar movimentos extremamente rápidos. Como os humanos, Kanaimé geralmente caça em grupos para produzir a sua comida.

Nesse sentido, Kanaimé consiste primordialmente em um modo de fazer que se reconhece a posteriori pelas marcas que deixa no corpo da vítima. Em um ataque não fatal a vítima pode ter ossos quebrados, especialmente os dedos, bem como ter luxações nas articulações e nos ombros. O pescoço também pode ser manipulado de forma a induzir algum tipo de lesão espinhal e provocar dores nas costas. O objetivo aqui é incutir na vítima uma quietude ou passividade que a torna menos resistente a outros ataques. Esse tipo de ataque é geralmente considerado apenas preliminar para a mutilação real e a morte. A maioria das vítimas se recupera da agressão inicial, mas é um processo humilhante e doloroso, podendo produzir complicações físicas no longo prazo. Como parece ser a intenção do ataque primário, as vítimas passam a sofrer o estresse de estarem cientes que o algoz as conhece e que irá revisitá-las para agressão fatal.

Os ataques definitivos são extremamente violentos. Geralmente, a vítima confronta-se com um único Kanaimé e em seguida é atingida por trás e, se já não estiver inconsciente, é fisicamente contida pelos outros. A vítima é tratada com um pó feito a partir de plantas adstringentes, sua língua é perfurada utilizando 
presas de uma cobra venenosa, ou lascas de madeira. Um rabo de iguana ou de tatu é empurrado em seu reto e os músculos do ânus retirados por friç̧ão.

A marca definitiva da morte por Kanaimé é a violação da genitália ou aparelho excretor e a introdução de folhas, raízes e até objetos de metal no lugar das entranhas da vítima. Um resultado é que o pescoço e os membros do corpo do morto ficam moles, ao invés da esperada rigidez cadavérica. Os mortos por Kanaimé apresentam a língua perfurada e às vezes também os pés, além de marcas roxas por todo o corpo. A inserção de ervas pelo ânus tem por objetivo dar início a um processo de autodigestão, criando o aroma especial de Kanaimé. Nas vítimas, o cheiro de abacaxi é um sinal de ataque, já para os assassinos, esse odor é o rastro da "comida" a ser produzida pelos corpos após o enterro. Como as vítimas ficam sem condições de falar, de beber água e perdem o controle intestinal, nos procedimentos médicos a causa clínica das mortes é geralmente dada como desidratação aguda por diarreia. O cheiro de pimenta no ambiente também é considerado um indicador forte da morte por Kanaimé.

Mas o ritual entre Kanaimé e sua vítima não termina com a morte. Como a finalidade de matar não é o desaparecimento da pessoa, mas a produção ritual do corpo como alimento, após o ataque fatal o Kanaimé tenta descobrir o lugar onde sua vítima foi enterrada e aguarda o início do cheiro de putrefação do cadáver, o que geralmente ocorre dentro de três dias. Durante esse período o Kanaimé entende-se vulnerável pois, ao tentar cheirar os primeiros estágios de putrefação, pode ser interceptado e morto pelos parentes do morto. Alguns tipos de proteção são realizados para evitar que o Kanaimé revisite o cadáver, como a colocação de uma armadilha de caça sobre a sepultura e a utilização de substâncias repelentes como pimentas, gasolina ou venenos de pesca. Muitas vezes os parentes tentam esconder o cadáver em uma rocha e cobrir o túmulo com grandes pedregulhos ou em um recipiente selado de cerâmica, mantendo em segredo o local. Quando o Kanaimé não consegue descobrir a localização do corpo ou é impedido de devorar o cadáver da vítima, ele fica quente, isto é, enfurecido, e seus avatares animais, identificados sobretudo na forma de tamanduás, zanzam enlouquecidos pelo campo.

Quando a sepultura é descoberta, uma vara é inserida através do chão diretamente até o cadáver e um líquido é sugado. Os sucos de putrefação são descritos como mel por causa de sua doçura. O uso desse canudo pelo Kanaimé equivale-se ao que fazem os tamanduás quando sugam formigas ou as plantas 
quando sugam nutrientes através de suas raízes. $\mathrm{O}$ fato de produzir comida e não a morte é simbolicamente central para a ação ritual do Kanaimé. O que o Kanaimé prova no túmulo é uma espécie de comida "divina". Ele precisa consumir o suco para expurgar as forças perigosas que estão dentro de si representadas como emissários espirituais, fazendo com que retornem à vítima. O suco também é retratado como um presente dos assassinos adeptos de Kanaimé para o xamã, que é quem os leva e dirige seus ataques. Esses presentes da morte do Kanaimé para seus xamãs são parte das trocas intermináveis entre animais e humanos sob o disfarce de caçador e presa.

Particularmente entre os Wapichana, plantas participam da ação kanaimé sendo usadas como ingredientes de venenos e também mastigadas ou esfregadas no corpo, quando oferecem poderes extraordinários de movimento. Logo, a técnica xamânica de ataque consiste em grupo de movimentos e atos que envolve a manipulação de determinadas plantas. Até aqui apresentei os padrões da ação kanaimé como operação xamânica. Na próxima secção apresento o relato de uma pessoa que viveu esse processo.

\section{O mau encontro}

Sr. Nazareno, interlocutor ao qual me referi no início deste artigo, viveu a experiência de um ataque. Esta narrativa me foi apresentada por ele enquanto realizava trabalho de campo em Jacamim, no ano de 2011. Sr. Nazareno estava na casa dos 60 anos e morava com a esposa na localidade conhecida como Mangueirão, à margem do rio Tacutu, linha d'agua que marca a fronteira entre $\mathrm{o}$ Brasil e a Guiana.

O senhor já ouviu falar Kanaimé? Chama Kanaimé. Esse negócio, quem inventou isso foram os Macuxi, aí os Wapichana aprenderam com os Macuxi já. [...]

Os Macuxi que inventou ele. Eles tinham plantas, as plantinhas deles. Um negócio de planta, que vira planta assim. Ele passa nos olhos dele e nas canelas, nos pés dele e passa assim, virava para outro bicho.

É o Macuxi que sabe. Passa assim, aí vira, aí some. Assim: tu estás bem aqui sentado, quando chega bem perto tu não vê ele não. É só através daquela planta dele. Se pegar aquilo de uma vez, naquela hora que ele está misturado na planta dele 
e para você matar, na hora não aparece mais nada. Mas pode ver aqui, que é como gente, igual gente, pode dar um tiro nele, ele some de uma vez, você procura de novo, cadê ele? Ele não está mais.

Ele já voltou lá com o dono. Então o dono fica no estado daquele, fica mandando dali, esse daí, tipo de gente mesmo, o tipo de gente, é pura gente. Daí você mata ele, mas some de uma vez. Tá! Tá! Pula assim, vira de capivara, vira de não sei o quê, vira de onça. Apareceu aqui ó, sumiu. É muito isso.

Eu passei dois anos vendo isso brincando comigo. Até o meu sobrinho não anda mais comigo. Minha mulher ficava chorando, dizendo: "Kanaimé vai te matar". Eu dizia: "Se vier me matar, eu acabo com ele antes, eu não tenho medo não." Mas rapaz, eu sofri demais. Doeu, doeu, doeu. Era só eu, minha mulher e dois filhos. Macuxi começou com papai. Eles vinham aqui, era o genro do Macuxi. E vieram com outro cidadão para vender cavalo, e esse cara vendeu o cavalo mais caro. Aí chegou outro e vendeu baratinho. Então ficou brabo porque ninguém comprou o cavalo deles, ficou zangado com papai. Aí falava: "Vou mandar, vou matar ele." Daí vinha para saber quem é o João Peixe, o apelido do meu pai. Nome dele João Peixe. Daí encontrou comigo lá na roça [riso tenso]. Eu tinha um rifle 22 e andava com um bocado de cartucho. Caso aparecesse um bicho. Aí encontrou comigo, nem conhecia ele, e perguntou: “Onde João Peixe mora?” Rapaz, o João Peixe, eu sei não... Ele acertou, mas não acertou meu pai, acertou eu. Essas horas eu estava lá voltando do igarapé. “Mas para que tu queria João Peixe?" Ele respondeu: “Queria saber onde ele está." Me zanguei logo: "Mas para que você quer saber onde está João Peixe?"

Acho que ficou com raiva me rondando. Quer saber de uma coisa? Eu larguei no peito dele, pá!

Ele parecia só cara. Aqui só negócio de folha. Aqui tudo enrolado com folhazinha assim, com um bocado de galho de pau, um negócio diferente.

Vou largar chumbo nele. Mandei bá! Ele pulou assim. Eu pensei: “Agora sim, agora eu vi Kanaimé!"

Era um mato como daqui assim, para sair na mata, ele me cercou lá quase saindo do mato, daí depois da roça. Mas daí eu corri, corria, outro queria me fechar e eu pá! Mandei de novo nem sei se o chumbo pegou. Dei uma carreira, e pensava: "Não sei se o chumbo pegou", entrei lá no igarapé.

Quando cheguei aqui, fui tomar banho, aí deu febre, febre, febre. E eu fiquei falando, eu estava aqui falando à toa, ninguém sabia mais. Eu fiquei falando, 
com uma febre doida, nesse dia eu até caguei na minha rede, não tinha vergonha de contar não. Com três dias eu fiquei ruim. Papai me perguntou e eu contei para ele que Kanaimé estava lá.

Ele disse: "Vai te matar." [...]

A cara dele diferente da gente, tudo enrolado com um chapeuzinho, não sei o que era. A cara dele toda pintada. E ele disse: "Não meu filho, você agora não vai sair sozinho mais."

Cinco vezes me deu febre, depois de cinco vezes não dava mais certo, você podia matar ele que não adiantava.

Um velho me contou: "O que você acertou foi só a planta dele. O dono fica longe." Não podia matar ele. Eu não sabia. [...] É assim o Kanaimé. Isso que chama Kanaimé, só é coisa de Macuxi. Tem raiva do Wapichana esse Macuxi.

Tem muito aí, tem muito aqui na Guiana, aí perto na Serra de Lethem. Lá que tu vê. Uma vez eu trabalhei nove meses lá perto. A gente ouvia ele assoviando, basta estar perto, era própria gente mesmo, só que Macuxi. Esse é que chama Kanaimé. Agora tem uns pajés, tem muito tipo de pajé. Agora tem tudo, só para estragar gente. Não é para curar gente não, antigamente pajé bom de doença: bate folha e cura que amanhã você estava bonzinho, agora não tem mais. Eu me lembro bem dos pajés antigos. Batia folha, levanta e sai andando já. Agora o pajé diz que bate folha, não bate não. Vai é acabando com gente. Tem algum que... tem uma porção para estragar gente, aí na Guiana tem demais.

Bicho ligeiro, é ligeiro, quando tu olha aqui, está bem aqui já. [assobio]. Assim que identifica. Nem os meus irmãos não conhecem.

Depois veio um velhinho me curar. Diz que foi lá com a mulher dele, tirou o cabelo da beirinha da vagina da mulher, queimou, botou dentro de uma garrafinha. Era ruim... igual cabelo queimado. Mas nunca mais vi Kanaimé. Ando muito, ando sozinho, de noite, já está com mais de 30 anos e nunca vi mais, até agora. (Sr. Nazareno, Jacamim, 2011).

\section{Humano-planta}

A relação humano-planta que atravessa a narrativa cria uma zona de indiscernibilidade que suspende as qualidades pretensamente intrínsecas de cada ente: plantas que transformam-se em bichos - bichos que ora aparecem como 
humanos, que ora aparecem como animais. Como sintetizou Nancy Foster (1993), a palavra Kanaimé refere-se ao menos a três coisas entre os Wapichana: a uma planta; uma pessoa conjectural que ataca sua vítima com a planta; e o fenômeno geral da morte atribuída ao comportamento extremamente antissocial.

A lógica utilizada para classificar as plantas é um ponto privilegiado de análise do universo do conhecimento esotérico e sua distribuição espacial entre os Wapichana. Segundo Farage (1997) o sistema de classificação botânica é baseado na capacidade humana de interferência e domínio frente às plantas. Aqui interessa especificamente a categoria wapananinao, que se trata de uma qualidade de plantas que escapam à esfera do cultivo, sem, no entanto, pertencerem à classe de plantas que estão na mata. As wapananinao são consideradas possuidoras de magia, não apenas porque são veículos para fórmulas mágicas, mas porque são elas mesmas geradoras de magia. A posse e o uso dessas plantas não devem ser de conhecimento público. Se perguntadas diretamente, as pessoas invariavelmente negam possuí-las.

As wapananinao são, em sua maioria, plantas das famílias Ciperaceae e Cactaceae, mas o catálogo é aberto a novas inscrições geralmente feitas por testes de aplicação. Brotam no inverno, quando é possível ouvir seus assovios, e secam no verão. Sr. Nazareno explicou que uma das plantas usadas por Kanaimé é "igual cebola, um redondo assim, igual cebolinha mesmo". Perguntei-lhe pelo nome em wapichana e ele respondeu: "Kusup, é kusup, é aquilo tudinho, redondo assim" - o que o dicionário da língua explica ser o tajá, planta também conhecida na Amazônia de modo geral como tinhorão, muito cultivada em jardins e reconhecida tanto por suas propriedades tóxicas quanto medicinais. Cientificamente, essa planta tem o nome de Caladium bicolor e pertence à família Araceae.

Com efeito, as plantas wapananinao são cultivadas exclusivamente nos terreiros das casas. Geralmente, o lugar das wapananinao no terreiro é um canto discreto e protegido por estacas que lhes protegem a identidade aos olhos de estranhos. Essas plantas têm origem incerta. Uma das possíveis explicações diz que estas plantas surgiram das cinzas da cobra - "oropiro", que habita os altos montes no vale do Rupununi. Os homens as teriam encontrado e aprendido a utilizá-las por método tentativo, tendo surgido assim magias de caça e de pesca.

Farage assinala uma propriedade fundamental das wapananinao: tal como os humanos, essas plantas possuem uma alma que lhes confere intenção 
e vontade. Plantas wapananinao não se cultivam, elas vivem junto daqueles que delas melhor cuidam. Insatisfeitas com os cuidados que lhes são dispensados, elas podem mudar-se de lugar, o que é atestado por sua aparente morte material. Enfurecidas, elas também podem voltar-se contra o dono e inclusive matá-lo.

Sua posse e uso variam conforme o sexo e a especialização. Homens e mulheres desenvolvem usos diversos dessas plantas e o conhecimento de um e outro não é passível de intercâmbio entre os sexos - sob a pena de perda da eficácia. O principal meio de circulação dessas plantas é a troca, sistema no qual são itens extremamente valorizados. A venda é considerada reprovável, além de ineficaz. Comercializadas, as wapananinao podem ficar aborrecidas, e recusarem-se a seguir os novos possuidores. Além disso podem voltar-se em vingança contra aqueles que as venderam. Podem ser também herdadas de consanguíneos e cônjuges. Por possuírem, como os humanos, uma alma, as wapananinao também possuem a potência da fala, o que torna possível a comunicação entre elas e seus "donos". Os cuidados dispensados as wapananinao envolvem principalmente o fornecimento de tabaco, através de infusão, fumaça ou mesmo esparramado o fumo sobre a terra. A fumaça soprada é altamente apreciada pelas wapananinao. Através da defumação, o dono conversa com a planta, que, nas sessões terapêuticas, lhes contam quais são as doenças, quais são os remédios.

A diferença entre uma utilização laica e uma especializada é traçada pelo ato de ensinar as plantas a cantar, potencialidade ativada pela alimentação com tabaco. Mas se a alimentação com tabaco é um ativador da magia da planta, que a permite, através do canto, falar aos humanos sobre doenças e curas, a alimentação com sangue é outro poderoso ativador de suas forças, seja de cura, de caça ou de vingança. É nesse sentido que se explicam aqueles que "estragam" suas plantas oferecendo-lhes sangue para lançá-las à vingança e à devoração dos humanos - convergindo para o que os Wapichana designam por Kanaimé. Uma vez que já experimentaram o sabor do sangue, essas plantas o vão querer sempre. Carne e sangue de caça então devem lhe ser oferecidos com regularidade, caso contrário, as plantas podem se enfurecer e atacar aqueles que delas cuidam. Não são raros os casos de homens que foram mortos por suas plantas depois de negligenciarem alimentação de caça. Sangue e tabaco, portanto, refinam a arte do canto, ao mesmo tempo em que desatam a virtualidade animal 
e humana das plantas wapananinao. Em resumo, as plantas wapananinao são aquilo que seu cuidado faz delas. Elemento central no universo do xamanismo, encontramos nas plantas ambiguidade equivalente ao status do xamã.

O que me interessa é essa lógica de uso ou manipulação que dá forma ao nexo humano-planta no grupo de movimentos singular do campo operacional do xamanismo como técnica de estragar os outros. Essa observação parece estar em consonância com a crítica de sr. Nazareno à ética xamânica apoiada em um fundamento técnico. Um ponto ressaltado por ele é a diferença entre as técnicas xamânicas como critério na distinção entre o pajé bom (marinao/ rezador), aquele que bate folhas, e o pajé ruim (chanaminuru), que faz Kanaimé. Segundo sr. Nazareno, a presença de velas é o indicador de que a tradição de conhecimento está sendo alterada pela incorporação de elementos de outras tradições, como a "macumba" dos maranhenses. As plantas e o uso que se faz delas são critérios para definir a essência do trabalho do marinao, que é bater folhas no escuro durante as sessões de cura, enquanto o chanaminuru manipula, come, esfrega no rosto e manda sua planta atacar os outros, estragar as pessoas. Estaríamos diante de um campo operativo de técnicas no corpo (Mauss, 2003), do matador e da vítima.

Outro ponto crítico é o modo de lidar com os ataques. Dentro da tradição indígena o Kanaimé pode ser morto publicamente (Mussolini, 1980). A casa do grupo familiar pode ser derrubada e as plantas arrancadas. No início do século XX, Farabee observava a influência da "legislação dos brancos" na supressão desses assassinatos e o desespero dos Wapichana por não poderem eliminar os maus pajés. Tal interferência desagradava, pois deixava as comunidades reféns desses assassinos. Segundo G. Mussolini, a influência dos missionários reduziu significativamente as reações comunitárias orientadas pelos marinao.

Em um episódio ocorrido há alguns anos em Jacamim, sr. Nazareno me contou como a situação foi enfrentada pela comunidade. Em um contexto de proliferação de doenças, um grupo consultou um pajé para saber quem era o Kanaimé. O pajé apontou que seria Damásio, um homem de baixa estatura, mas muito valente que teria vindo da Guiana, da região de Lethem, fugido de lá. Damásio era um pajé ruim que vinha para estragar os outros. Então um grupo de homens liderados pelo tuxaua encontrou as plantas dele - prova de que era ele mesmo o agente das mortes na comunidade. Quando cercaram Damásio ele estava transtornado, ficava rodando, pulando e batia palmas freneticamente. 
Os homens ameaçavam amarrá-lo e jogá-lo dentro de um poço. Cercado, o próprio Damásio teria colocado uma corda no pescoço e cometido suicídio. "Acabou com ele, acabou com a doença." Contudo, mesmo depois de o indivíduo ter se enforcado publicamente, o Kanaimé não teria morrido. Na verdade, ele já havia passado para outro domínio, através das plantas, porque outra pessoa que convivia com Damásio ficou com as plantas dele, e, como sr. Nazareno sintetizou: "A planta dele que é o ruim."

\section{Sobre a ética dos xamãs}

A descrição etnográfica apresentada até aqui nos leva aos dois aspectos indissociáveis que interessam à análise do xamanismo como fronteira. De um lado a condição humana e de outro a ética. No contexto do maciço guianense ocidental esses dois pontos já tinham sido aventados por Koch-Grünberg e ganharam desenvolvimento no trabalho de Joanna Overing $(1985,1991,2002)$ a partir de seu trabalho com os Piaroa. Em Reason and morality, Overing (1985) reuniu um conjunto de colaboradores que discutiram para o contexto amazônico algo que Evans-Pritchard tinha colocado como problema fundamental a partir da etnografia zande: a heterogeneidade constitutiva da razão ao fundamentar que nos modos de conhecimento em diversas sociedades indígenas a racionalidade é indissociável de seus sistemas morais. Em outro trabalho, Overing (1991) destaca o papel do "conhecimento produtivo" na construção política e moral da comunidade. É produtivo ou estético o conhecimento que permite a manutenção da comunidade e provê a força criativa para a sua continuidade. Nesse sentido, a categoria "conhecimento produtivo" não se refere apenas às capacidades que permitem o uso de recursos da terra, mas também àquelas que permitem 0 tato, isto é, a habilidade de viver, pacífica e sociavelmente, em relações cotidianas com outras pessoas (Overing, 1991). E esse fato de os postulados indígenas sobre a realidade nunca serem descontextualizados dos aspectos sociais, políticos e morais da prática cotidiana não é uma questão trivial (Overing, 1995). Esse conhecimento expressa uma filosofia da vida social baseada na ideia de que a comunidade existe mediante o contato entre entidades e forças, diferentes entre si, e apenas por meio de tal mistura "adequada" a existência social pode ser conquistada e o perigo, afastado (Overing, 2002). 
A ação kanaimé aciona um modo de conhecimento que atenta justamente contra essa convivência pacífica com os outros. Ele coloca em relevo as rupturas com a ética da convivialidade no sentido elaborado por Overing e Passes (2000) que envolve tanto a busca pela convivência tranquila quanto uma metafísica das relações entre o humano e não humano. Essas considerações encontram forte ressonância nas perspectivas indígenas encontradas no contexto regional aqui tratado. Elas podem ser sintetizadas em uma categoria: antaminchan - que significa "estragar" os outros.

Um último fragmento etnográfico explicita bem as reflexões indígenas contemporâneas sobre a ética do xamã. Certa manhã, toda essa discussão sobre princípios e valores morais do xamã surgiu em uma analogia formulada pelo tuxaua de Jacamim que sintetiza bem como os Wapichana estão percebendo e avaliando o conhecimento xamânico. Em 2011, o mundo das metrópoles foi tomado pela disseminação do vírus Influenza A H1N1, conhecido como gripe suína. O governo brasileiro então deu início a campanhas nacionais de vacinação contra a doença, priorizando a vacinação de povos indígenas. Naquela ocasião, os agentes indígenas de saúde (AIS) foram acionados para informar a população do agendamento para vacinação das comunidades contra o vírus. No momento em que a informação sobre a agenda de vacinação contra a gripe suína chegou em Jacamim, um professor me perguntou o que eu pensava sobre o surgimento de tal doença. Eu disse a ele que não tinha conhecimento detalhado sobre a origem do novo vírus, mas coloquei que tinha minhas desconfianças quanto ao surgimento dessas doenças novas, que se espalham rapidamente, e para as quais logo depois algum laboratório do mundo fornece a vacina ou o remédio. Então o tuxaua disparou: "Os laboratórios estão iguais aos nossos pajés atuais." Perguntei, como? E ele então completou o raciocínio: "Rapaz, hoje pajé cobra 200, 500 reais para curar, dizer que vai curar. Só para soprar ali rapidinho; 400, 500 reais, uma bicicleta. Estão iguais aos laboratórios, eles mesmos dissipam doenças e depois oferecem a cura."

Nas construções sociais que são feitas hoje sobre o papel e a validade do conhecimento xamânico muitas são pautadas em uma crítica muito forte à postura ética desses especialistas. Essa crítica é direcionada à sobrevalorização das consultas e a mudanças na extensão dos tratamentos, que passaram a levantar suspeitas sobre a postura do xamã e de seus interesses financeiros em protelar etapas de tratamento com vistas a aumentar o faturamento. 
A combinação de técnicas e procedimentos derivados dos intercâmbios estabelecidos com outras tradições de conhecimento também é vista com olhos críticos. O postulado básico é claro: bom pajé utiliza apenas tabaco e bate folhas, no escuro.

Hoje não tem mais pajé. Tem, mas é pajé velho, mentiroso, que quer ganhar dinheiro. Porque Deus nos deixou aí para não cobrar ninguém. Agora, quem sabe curar, quem é pajé, é para ajudar mesmo, quem quiser dar gratificaçãozinha, a gente aceita. Sobre isso aí eu já falei muito para as pessoas aqui também. Não é para fazer mal para os outros, não é para estragar os outros, não é para fazer virar Kanaimé para os outros, não é... (Benedito, Jacamim, 2011).

A essa altura, Benedito ressalta a moralidade constitutiva dos usos desses conhecimentos e esboça uma crítica à ética dos pajés velhos, em uma linha semelhante àquela desenvolvida por sr. Nazareno. Como foi apresentado, na trajetória de um especialista, a vida de pajé e a vida de Kanaimé são duas dimensões sempre presentes e marcam o caráter ambíguo que se atribui aos detentores e praticantes desses conhecimentos.

\section{Considerações finais}

Neste artigo procurei elaborar uma análise etnográfica do xamanismo de estilo agressivo conhecido na região do maciço guianense ocidental como Kanaimé. Apresentei um esboço do campo de operação do ataque kanaimé privilegiando perspectivas elaboradas pelos Wapichana. No relato de um mau encontro transcrito, as relações humano-planta aparecem como expressão de como os Wapichana compreendem a alteridade e elaboram, ou melhor, matizam as fronteiras entre o humano e o não humano. Esse relato de um processo de agressão e cura indica um caminho produtivo para "refletir sobre a capacidade de agir ou, em outros termos, sobre uma teoria indígena da ação" (Sztutman, 2005, p. 176). Nestas considerações finais tentarei extrair algumas implicações nessa direção.

O xamanismo nas Guianas, já consideradas as exceções, pode-se argumentar seria de tipo "horizontal". A agressividade e a capacidade de causar doenças, 
isto é, de "estragar os outros" são características das formas de atuação desses xamas horizontais, que alimentam a ambiguidade moral da figura do "xamã" e geram, como se viu, constantes reflexões locais sobre a ética.

As configurações contemporâneas das práticas xamânicas na confecção das redes de relações de que participam os Wapichana indicam o caráter aberto, a força e a heterogeneidade desse modo de conhecimento. Nesse sentido, um refinamento da análise etnológica pode advir de uma abordagem processual em lugar de uma perspectiva sistêmica do xamanismo, levando a atenção etnográfica para o "campo de operação", para as técnicas, como via privilegiada para uma teoria indígena da ação.

A definição wapichana para o chanaminuru parece bem próxima do xamã horizontal que Viveiros de Castro (2008, p. 20) qualificou de "sacrificador-vítima" ao extrair implicações instigantes do esquema sacrificial maussiano para a compreensão do xamanismo. Em contraste com o caráter metafórico do totemismo, o sacrifico é um "sistema técnico de operações". Mas, antes que "sistema", o esquema sacrificial designaria um tipo de descrição para as zonas ou momentos de indiscernibilidade entre "xamãs-sacrificadores" e suas vítimas humanas.

Viveiros de Castro aciona duas noções elaboradas pelo filósofo da técnica Gilbert Simondon (2005), a primeira é transdução, para dizer que as transformações sacrificiais acionam relações intensivas que modificam a natureza dos termos na medida em que "fazem passar" algo entre eles, qualificando essas transformações como transduções que lançam mão de uma "energética do contínuo". Entretanto, seguindo o argumento do autor, o xamanismo amazônico não se reduz ao esquema maussiano, e se de um lado as operações xamânicas são irredutíveis ao jogo simbólico do totemismo "tampouco são da mesma espécie que o contínuo fusional perseguido pela interserialidade imaginária do sacrifício" (Viveiros de Castro, 2008, p. 24). Aqui surge outra categoria simondoniana, "pré-individual" ao argumentar que as operações xamânicas "exemplificam uma terceira forma de relação, a comunicação entre termos heterogêneos que constitui multiplicidades pré-individuais, intensivas ou rizomáticas" (Viveiros de Castro, 2008, p. 24).

O tipo de fenômeno aqui apresentado visto como um grupo particular de movimentos relaciona humanos e plantas não como elementos já individuados, constitutivos de um sistema, mas dando primazia à ontogênese técnica 
dos seres e aos atos de transdução que mobilizam forças do cosmo, e suscita a proposição do xamanismo como essa zona interespecífica obscura, que estou referindo como fronteira, matizada e enviesada entre humanos e não humanos. Com o suporte das ideias de Simondon, que aqui cabe apenas sinalizar, não se trata de desconsiderar seus contornos, mas de interrogá-los a partir das multiplicidades pré-individuais, dos processos de ontogênese e das forças de transdução. Em suma, dar primazia à energia como fundamento das relações. Pois, como me disse sr. Nazareno, "existe muita ruindade rodando no mundo".

\section{Referências}

ÁVILA, T. A. M. de. Biopirataria e os Wapichana: etnografia sobre a bioprospecção e o acesso aos recursos genéticos na Amazônia Brasileira. Revista de Estudos e Pesquisas, Brasília, v. 3, n. 1/2, p. 225-260, jul./dez. 2009.

BAINES, S. G. Os índios makuxi e wapichana e suas relações com Estados Nacionais na fronteira Brasil-Guiana. Brasília: UnB, 2003. (Série Antropologia n. 338).

BAINES, S. G. Entre dois Estados Nacionais: perspectivas indígenas a respeito da fronteira entre Guiana e Brasil. Anuário Antropológico/2005, Rio de Janeiro: Tempo Brasileiro, p. 35-49, 2006.

BARTH, F. O guru e o iniciador: transações de conhecimento e moldagem da cultura no sudeste da Ásia e na Melanésia. In: BARTH, F. O guru, o iniciador e outras variações antropológicas. Rio de Janeiro: Contra Capa, 2000. p. 141-165.

COLSON, A. B. Routes of knowledge: an aspect of regional integration in the circum-Roraima area of the Guiana Highlands. Antropológica, Caracas, n. 63-64, p. 103-149, 1985.

DESCOLA, P. Societies of nature and the nature of society. In: KUPER, A. (Ed.). Conceptualizing society. London: Routledge, 1992. p. 107-126.

FARABEE, W. C. The Central Arawaks. New York: University of Pennsylvania, 2009.

FARAGE, N. As flores da fala: práticas retóricas entre os Wapichana. 1997. Tese (Doutorado em Estudos Comparados em Literaturas de Língua Portuguesa)-Faculdade de Filosofia, Letras e Ciências Humanas, Universidade de São Paulo, São Paulo, 1997.

FOSTER, N. F. Kanaima and Branco in Wapisiana cosmology: cosmology, values, and inter-ethnic contact in South America. South American Indian Studies, n. 2, p. 23-30, Sept. 1993. 
GALLOIS, D. T. (Org.). Redes de relações nas Guianas. São Paulo: Associação Editorial. Humanitas: Fapesp, 2005.

HUGH-JONES, S. Shamans, prophets, priests and pastors. In: THOMAS, N.; HUMPHREY, C. (Ed.). Shamanism, history, and the state. Ann Arbor: University of Michigan Press, 1996. p. 32-75.

KOCH-GRÜNBERG, T. Del Roraima al Orinoco: vol. III. Caracas: Ed. Banco Central de Venezuela, 1982.

LATOUR, B. Jamais fomos modernos. São Paulo: Editora 34, 1994.

MAUSS, M. As técnicas do corpo. In: MAUSS, M. Sociologia e antropologia. São Paulo: Cosac Naify, 2003. p. 399-424.

MELATTI, J. Guianense Ocidental. In: MELATTI, J. Áreas etnográficas da América Indígena. 2016. Disponível em: <http://www.juliomelatti.pro.br/areas/e2guocid.pdf>. Acesso em: 29 maio 2017.

MUSSOLINI, G. Notas sobre os conceitos de moléstia, cura e morte entre os índios vapidiana. In: MUSSOLINI, G. Ensaios de antropologia indígena e caiçara. São Paulo: Paz e Terra, 1980. p. 193-215.

OVERING, J. (Ed.). Reason and morality. London: Tavistock, 1985.

OVERING, J. A estética da produção: o senso da comunidade entre os Cubeo e os Piaroa. Revista de Antropologia, São Paulo, v. 34, p. 7-33, 1991.

OVERING, J. O mito como história: um problema de tempo, realidade e outras questões. Mana, Rio de Janeiro, v. 1, n. 1, p. 107-140, 1995.

OVERING, J. Estruturas elementares de reciprocidade: notas comparativas sobre a Guiana, o Noroeste Amazônico e o Brasil Central. Cadernos de Campo, São Paulo, v. 10, n. 10, p. 121-138, 2002.

OVERING, J.; PASSES, A. Introduction: conviviality and the opening of Amazonian anthropology. In: OVERING, J.; PASSES, A. (Ed.). The anthropology of love and anger: the aesthetics of conviviality in Native Amazonia. London: Routledge, 2000. p. 1-30.

SANTILLI, P. Fronteiras da República: história e política entre os Macuxi no vale do rio Branco. São Paulo: NHII-USP: Fapesp, 1994.

SCHOMBURGK, R. H. Travels in Guiana and on the Orinoco during the years 1835-1839. Georgetown: The Argosy Company, 1931.

SIMONDON, G. L'individuation à la lumière des notions de forme et d'information. Grenoble: Éditions Jérôme Millon, 2005. 
SZTUTMAN, R. Sobre a ação xamânica. In: GALLOIS, D. T. (Org.). Redes de relações nas Guianas. São Paulo: Associação Editorial Humanitas: Fapesp, 2005. p. 151-226.

VIDAL, S. M.; WHITEHEAD, N. L. Dark shamans and the shamanic state: sorcery and witchcraft as political process in Guyana and the Venezuelan Amazon. In: WHITEHEAD, N. L.; WRIGHT, R. (Ed.). Darkness and secrecy: the anthropology of assault sorcery and witchcraft in Amazonia. Durham: Duke University Press, 2004. p. 51-82.

VIVEIROS DE CASTRO, E. Os pronomes cosmológicos e o perspectivismo ameríndio. Mana, Rio de Janeiro, v. 2, n. 2, p. 115-144, 1996.

VIVEIROS DE CASTRO, E. Xamanismo transversal. Lévi-Strauss e a cosmopolítica amazônica. In: QUEIROZ, R. C.; NOBRE, R. F. (Org.). Lévi-Strauss: leituras brasileiras. Belo Horizonte: Editora UFMG, 2008. p. 79-124.

WHITEHEAD, N. L. Dark shamans: Kanaimà and the poetics of violent death. Durham: Duke University Press, 2002. 